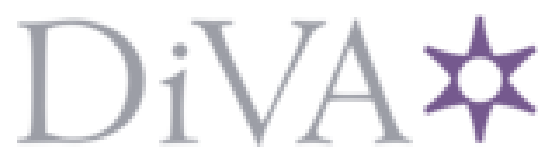

http://www.diva-portal.org

This is the published version of a paper published in Organic Syntheses.

Citation for the original published paper (version of record):

Jalalian, N., Olofsson, B. (2013)

Synthesis of Koser's Reagent and Derivatives.

Organic Syntheses, 90: 1-9

Access to the published version may require subscription.

N.B. When citing this work, cite the original published paper.

Permanent link to this version:

http://urn.kb.se/resolve?urn=urn:nbn:se:su:diva-75776 


\section{Synthesis of Koser's Reagent and Derivatives}

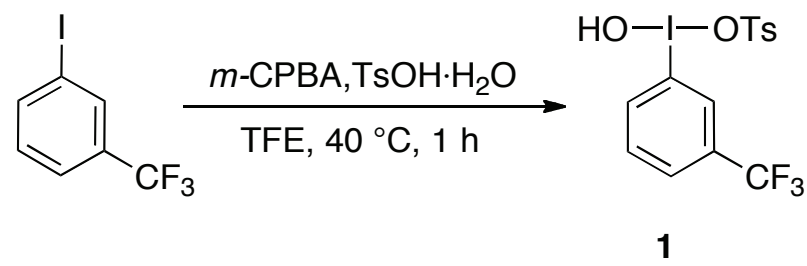

Submitted by Nazli Jalalian and Berit Olofsson. ${ }^{1}$

Checked by David Yeung, Stephen M. Shaw and Margaret Faul.

\section{Procedure}

1-[Hydroxy(tosyloxy)iodo]-3-trifluoromethylbenzene (1). A 250-mL single-necked, round-bottomed flask equipped with a magnetic stirring bar (3.5 $\mathrm{cm}$, egg-shaped) is charged with $m$-chloroperbenzoic acid ( $m$-CPBA, $4.18 \mathrm{~g}, 17 \mathrm{mmol}, 1.0$ equiv) (Note 1) and 2,2,2-trifluoroethanol (TFE, $65 \mathrm{~mL}$ ) (Note 2). The mixture is dissolved by sonication (Note 3) (approx. $20 \mathrm{~min}$ ) and the concentration of $m \mathrm{CPBA}$ is determined by iodometric titration of the solution (Notes 4 and 5). 3-Iodobenzotrifluoride $(2.45 \mathrm{~mL}$, $1.71 \mathrm{~g}, 17.0 \mathrm{mmol}, 1.0$ equiv) (Note 6) and $p$-toluenesulfonic acid monohydrate (3.23 g, $17.0 \mathrm{mmol}, 1.0$ equiv) (Note 7) are added to the solution. The flask is loosely capped with a septum, and the reaction mixture is lowered into a $40{ }^{\circ} \mathrm{C}$ preheated oil bath and stirred vigorously during $1 \mathrm{~h}$ (Notes 8 and 9). The solvent is then removed by distillation to recover the TFE (Note 10), or evaporated under reduced pressure if TFE recovery is not of interest (Notes 11 and 12). After concentration, diethyl ether $(65 \mathrm{~mL})$ (Note 13) is added to the residue and the mixture is allowed to stir for $30 \mathrm{~min}$, resulting in trituration of the product as a white solid. The product is collected by suction filtration on a Büchner funnel, followed by washing with diethyl ether $(65 \mathrm{~mL})$. The product is vacuum-dried at room temperature $\left(<1 \mathrm{mmHg}, 22{ }^{\circ} \mathrm{C}\right)$ to afford compound $\mathbf{1}$ as a white solid (7.66 g, 97\%) (Notes 14 and 15).

\section{Notes}

1. $m$-CPBA $(\leq 77 \%)$ was purchased from Sigma-Aldrich. Typical purity of samples received was $66-69 \%$ by weight. 
2. TFE ( $\geq 99 \%)$ was purchased from Sigma-Aldrich and used as received. The reaction is run without precautions to avoid air or moisture.

3. The sonicator used to dissolve $m$-CPBA was an $85 \mathrm{~W}$ ultrasonic cleaner from VWR, model B2500A-DTH.

4. The concentration of active oxidizing agent is determined by iodometric titration. ${ }^{2} \mathrm{NaI}(1.5 \mathrm{~g})$ is dissolved in distilled water $(50 \mathrm{~mL})$. Chloroform $(5 \mathrm{~mL})$, glacial acetic acid $(5 \mathrm{~mL})$ and approximately $0.67 \mathrm{~g}$ of $m$-CPBA solution are added and the mixture is stirred vigorously. The solution is titrated with aq. $\mathrm{Na}_{2} \mathrm{~S}_{2} \mathrm{O}_{3}(0.100 \mathrm{M})$ - the brown iodine color fades to yellow and then disappears. As a rough guide, $2 \mathrm{~mL} \mathrm{Na} \mathrm{Na}_{2} \mathrm{O}_{3}$ solution is required for $0.5 \mathrm{~g}$ of solution. The $m$-CPBA concentration is

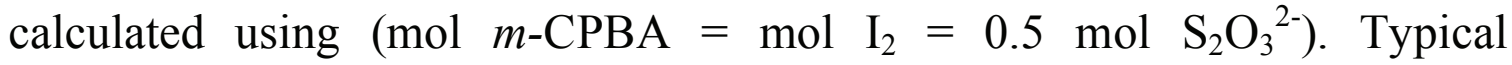
concentration of $m$-CPBA as determined by titration is approximately 3.0 $\mathrm{wt} \%$.

5. As an alternative to dissolving the $m$-CPBA in TFE via sonication for titration, the submitters reported the following procedure: To obtain a homogeneous powder, $m$-CPBA is dried under vacuum in a round-bottomed flask at room temperature until the flask is no longer cold. The time required depends on the amount of $m$-CPBA and the vacuum; $5 \mathrm{~g}$ requires approximately $1.5 \mathrm{~h}$ at $10 \mathrm{mmHg}$. The dried $m$-CPBA was stored for prolonged time in a refrigerator. Caution should be exercised, however, as dried $m$-CPBA is shock sensitive. The reaction performs well without drying of the $m$-CPBA (86-92\% yield), but the titration (see Note 4 ) of the heterogeneous $m$-CPBA becomes less reliable than when the dried or sonicated/dissolved material is used.

6. 3-Iodobenzotrifluoride (98\%) was purchased from Sigma-Aldrich and used as received.

7. $p$-Toluenesulfonic acid monohydrate ( $\geq 98.5 \%)$ was purchased from Sigma-Aldrich and used as received.

8. The flask does not need to be sealed. A slightly yellow precipitate is observed after 5 min and the mixture may become difficult to stir as the reaction proceeds and thickens; if this occurs, more TFE may be added. Both 1 and $m$-CBA (the reduced form of $m$-CPBA, which is a by-product of the reaction and present in the starting $m$-CPBA) are poorly soluble in TFE. The disappearance of iodobenzotrifluoride can be followed by TLC using neat pentane $\left(\mathrm{R}_{f}=0.83\right.$ using EMD TLC Silica Gel $\left.60 \mathrm{~F}_{254}\right)$ and visualized by UV. 
9. Reactions performed at higher temperatures $\left(60\right.$ or $\left.80^{\circ} \mathrm{C}\right)$ provide lower yield due to partial decomposition of $1\left(80^{\circ} \mathrm{C}\right.$ for $1 \mathrm{~h}$ gave $76 \%$ yield). The reaction may also be performed at room temperature but requires extended reaction time $(2 \mathrm{~h}$ reaction time gave $67 \%$ yield, $18 \mathrm{~h}$ gave $90 \%$ yield).

10. TFE is recovered using a short path distillation head and a $25 \mathrm{~cm}$ condenser under reduced pressure in a $40{ }^{\circ} \mathrm{C}$ oil bath $\left(\mathrm{bp}=28{ }^{\circ} \mathrm{C}\right.$ at $86 \mathrm{mmHg}$ ). The distillate is collected over $\sim 90 \mathrm{~min}$ with the receiving flask immersed in an ice bath. Vacuum should be applied in a controlled manner to prevent foaming. Experiments using microscale distillation resulted in lower recovery of TFE. Higher distillation temperatures should be avoided due to partial decomposition of $\mathbf{1}$. The TFE can be recovered almost quantitatively ( $63 \mathrm{~mL}, 97 \%$ ) and can be re-used without loss in yield.

11. The TFE can be removed by evaporation under reduced pressure using a rotary evaporator $\left(25^{\circ} \mathrm{C}, \sim 20 \mathrm{mmHg}\right)$, if recovery of the solvent is not of interest.

12. Unreacted $m$-CPBA, e.g. from charging excess $m$-CPBA, may pose a risk of explosion during evaporation of TFE since dry $m$-CPBA is shock sensitive. It is important that the concentration be carried out using an oil bath or water bath, not a heating mantle, to avoid heating the concentrated solids above $40{ }^{\circ} \mathrm{C}$. Due to the insolubility of $\mathbf{1}$ in TFE, the isolation is straightforward even if residual TFE remains. Direct filtration of the solid material from the crude reaction, without concentration, gave $\mathbf{1}$ in $77 \%$ yield after washing with diethyl ether $(65 \mathrm{~mL})$. Another $18 \%$ yield of 1 was obtained by concentration of the filtrate followed by precipitation with diethyl ether.

13. Diethyl ether $(\geq 99.0 \%)$ was purchased from Sigma-Aldrich and used as supplied.

14. The reaction was also performed at 5.0 and $13.0 \mathrm{mmol}$ scale to afford a comparable yield of 1 (2.16 g, 94\% and $5.69 \mathrm{~g}, 95 \%$, respectively).

15. The product is stable to air but somewhat light sensitive and is best stored in a refrigerator in the dark. Analytical data of 1: mp: $155-157^{\circ} \mathrm{C}$ (lit $\left.156-157^{\circ} \mathrm{C}\right)^{3} ;{ }^{1} \mathrm{H}$ NMR $\left(400 \mathrm{MHz}, \mathrm{DMSO}_{-} d_{6}\right) \delta: 2.29$ (s, $\left.3 \mathrm{H}\right), 7.12(\mathrm{~d}, J$ $=8.0 \mathrm{~Hz}, 2 \mathrm{H}), 7.48(\mathrm{~d}, J=8.0 \mathrm{~Hz}, 2 \mathrm{H}), 7.85(\mathrm{t}, J=8.0 \mathrm{~Hz}, 1 \mathrm{H}), 8.08(\mathrm{~d}, J$ $=8.0 \mathrm{~Hz}, 1 \mathrm{H}), 8.50(\mathrm{~d}, J=8.0 \mathrm{~Hz}, 1 \mathrm{H}), 8.63(\mathrm{~s}, 1 \mathrm{H}), 9.98(\mathrm{bs}, 1 \mathrm{H})$; ${ }^{13} \mathrm{C}$ NMR (100 MHz, DMSO- $\left.d_{6}\right) \delta: 20.7 ; 123.1$ (q, ${ }^{l} J_{F-C}, J=273.4 \mathrm{~Hz}$ ), $123.8,125.5,128.6\left(\mathrm{q},{ }^{3} J_{F-C}, J=2.8 \mathrm{~Hz}\right), 130.5\left(\mathrm{q},{ }^{3} J_{F-C}, J=3.5 \mathrm{~Hz}\right), 130.8$ $\left(\mathrm{q},{ }^{2} J_{F-C}, J=32.5 \mathrm{~Hz}\right), 131.9,138.0,138.6,144.0 ;{ }^{19} \mathrm{~F}$ NMR $(376 \mathrm{MHz}$, 
DMSO- $\left.d_{6}\right)^{4} \delta:-61.5$; IR (ATR $v$ 686, 794, 1199, 1319, $3076 \mathrm{~cm}^{-1}$; HRMS (ESI): calcd for $\mathrm{C}_{7} \mathrm{H}_{5} \mathrm{~F}_{3} \mathrm{IO}\left([\mathrm{M}-\mathrm{OTs}]^{+}\right)$: 288.9332; found 288.9330; Anal. Calcd. for $\mathrm{C}_{14} \mathrm{H}_{12} \mathrm{~F}_{3} \mathrm{IO}_{4} \mathrm{~S}$ (460.21): C 36.54; H 2.63. Found: C 36.4; H 2.6.

\section{Handling and Disposal of Hazardous Chemicals}

The procedures in this article are intended for use only by persons with prior training in experimental organic chemistry. All hazardous materials should be handled using the standard procedures for work with chemicals described in references such as "Prudent Practices in the Laboratory" (The National Academies Press, Washington, D.C., 2011 www.nap.edu). All chemical waste should be disposed of in accordance with local regulations. For general guidelines for the management of chemical waste, see Chapter 8 of Prudent Practices.

In the development and checking of these procedures, every effort has been made to identify and minimize potentially hazardous steps. The Editors believe that the procedures described in this article can be carried out with minimal risk if performed with the materials and equipment specified, and in careful accordance with the instructions provided. However, these procedures must be conducted at one's own risk. Organic Syntheses, Inc., its Editors, and its Board of Directors do not warrant or guarantee the safety of individuals using these procedures and hereby disclaim any liability for any injuries or damages claimed to have resulted from or related in any way to the procedures herein.

\section{Discussion}

Hypervalent iodine(III) reagents are mainly used as mild oxidants in organic synthesis. [Hydroxy(tosyloxy)iodo]benzene (HTIB, Koser's reagent) is employed in $\alpha$-oxidation of carbonyl compounds, oxidation of olefins, ring contractions and expansions, dearomatization of phenols and synthesis

of iodonium salts (Scheme 1). ${ }^{5}$ The reactivity of the reagent can be varied by adding substituents on the aryl moiety, and compound $\mathbf{1}$ is more efficient than HTIB in $\alpha$-oxidation of ketones. ${ }^{6}$ 


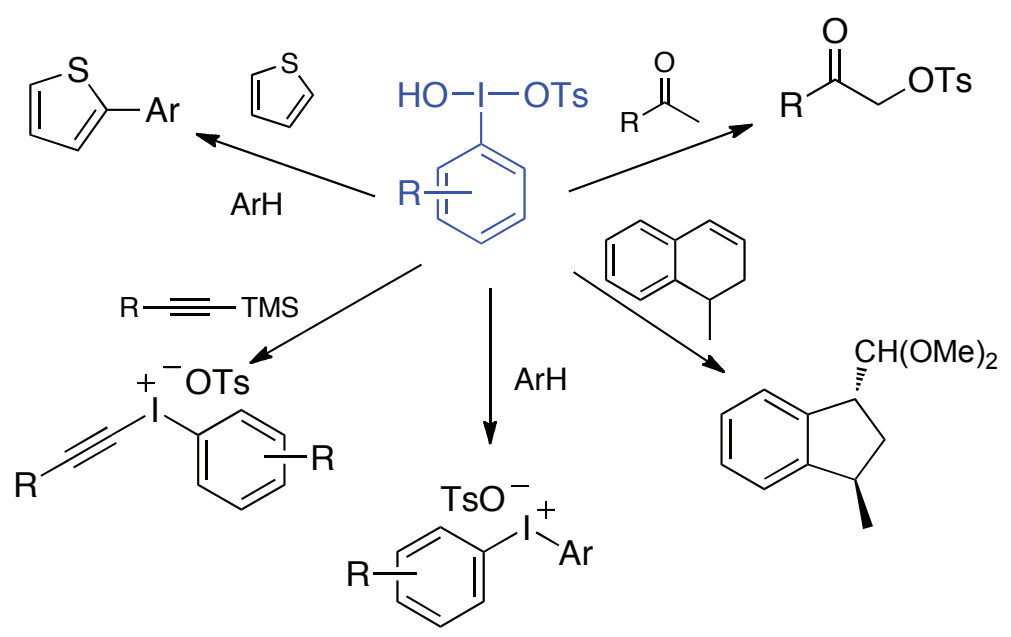

Scheme 1. Application areas of HTIBs.

[Hydroxy(tosyloxy)iodo]arenes (HTIBs) are usually synthesized from other iodine(III) reagents, but Yamamoto and Togo recently reported an efficient one-pot reaction where iodoarenes were treated with $m$-CPBA in chloroform at room temperature to give HTIBs in high yields. ${ }^{3}$

The one-pot synthesis of HTIBs from iodoarenes reported herein utilizes TFE as solvent, which reduces reaction times considerably. In our original report, a large scope of electron-rich and electron-poor HTIBs has been demonstrated (Table 1), and the synthesis of electron-rich HTIBs can be performed directly from iodine and arenes (Table 2). ${ }^{7}$ The reaction then employed a 1:1 mixture of $\mathrm{CH}_{2} \mathrm{Cl}_{2}$ and TFE to cut the solvent costs. Large scale preparations are benefitted from the use of neat TFE with recovery of the solvent, which is also preferable from an environmental point of view. 
Table 1. Synthesis of HTIBs from iodoarenes.

Field (\%)


Table 2. Synthesis of HTIBs from iodine and arenes.

Entry

${ }^{a}$ Sequential reaction with $m$-CPBA and TFOH followed by addition of TsOH.

1. Department of Organic Chemistry, Arrhenius Laboratory, Stockholm University, SE-10691 Stockholm Sweden. E-mail: berit@organ.su.se. The authors thank Prof. Hans Adolfsson for fruitful discussions. This work was financially supported by the Swedish Research Council and Wenner-Gren Foundations.

2. (a) Vogel, A. I.; Furniss, B. S.; Hannaford, A. J.; Rogers, V.; Smith, P. W. G.; Tatchell, A. R., Vogel's Textbook of Practical Organic Chemistry (4 ${ }^{\text {th }}$ Ed) 1978, p. 308. (b) Org. Synth, Coll. Vol. 6, 1988, 276; Org. Synth. 1970, 50, 15. 
3. Yamamoto, Y.; Togo, H. Synlett 2005, 2486-2488.

4. Fluorobenzene used as internal reference, see Fifolt, M. J.; Sojka, S. A.; Wolfe, R. A.; Hojnicki, D. S.; Bieron, J. F.; Dinan, F. J. J. Org. Chem. 1989, 54, 3019-3023.

5. (a) Zhdankin, V. V.; Stang, P. J. Chem. Rev. 2008, 108, 5299-5358; (b) Merritt, E. A.; Olofsson, B. Synthesis 2011, 517-538; (c) Koser, G. F. Aldrichimica Acta 2001, 34, 89-102.

6. Nabana, T.; Togo, H. J. Org. Chem. 2002, 67, 4362-4365.

7. Merritt, E. A.; Carneiro, V. M. T.; Silva, L. F. J.; Olofsson, B. J. Org. Chem. 2010, 75, 7416-7419.

\section{Appendix \\ Chemical Abstracts Nomenclature; (Registry Number)}

1-[Hydroxy(tosyloxy)iodo]-3-trifluoromethylbenzene; (440365-98-0)

$m$-Chloroperbenzoic acid; Peroxybenzoic acid, $m$-chloro-;

Benzenecarboperoxoic acid, 3-chloro-; (937-14-4)

2,2,2-Trifluoroethanol; Ethanol, 2,2,2-trifluoro-; (75-89-8)

3-Iodobenzotrifluoride; Benzene, 1-iodo-3-(trifluoromethyl)-; (401-81-0)

$p$-Toluenesulfonic acid monohydrate; Benzenesulfonic acid, 4-methyl-;

(104-15-4)

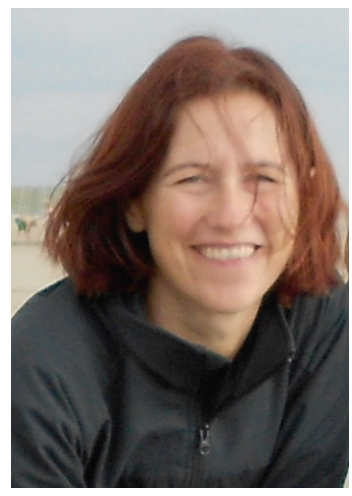

Berit Olofsson was born in Sundsvall, Sweden, in 1972. She got her M.Sc. at Lund University in 1998, and finished her $\mathrm{Ph} . \mathrm{D}$. in asymmetric synthesis at KTH, Stockholm in 2002, supervised by Prof. P. Somfai. She then moved to Bristol University, UK for a post doc on methodology and natural product synthesis with Prof. V. K. Aggarwal. Returning to Sweden, she became assistant supervisor in the group of Prof. J.-E. Bäckvall at Stockholm University. In 2006 she was appointed to Assistant Professor, and got a permanent position as Associate Professor in 2010. Her research is focused on the synthesis and application of hypervalent iodine compounds as environmentally benign reagents in asymmetric synthesis. 


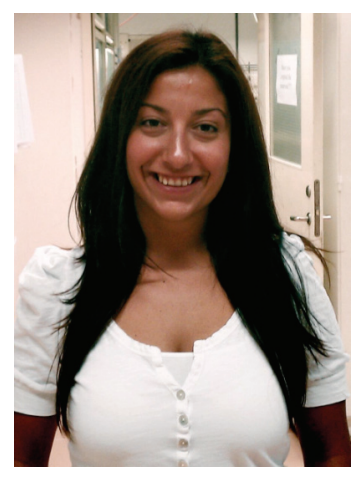

Nazli Jalalian was born in 1982 in Tehran, Iran, and moved to Sweden at the age of four. She studied Chemistry at Stockholm University, where she also started her Ph.D. studies in 2007, under the supervision of Berit Olofsson. She has developed synthetic routes to diaryliodonium salts and applied the salts in arylation of phenols to diaryl ethers. She is currently working with further applications of the salts in organic synthesis.

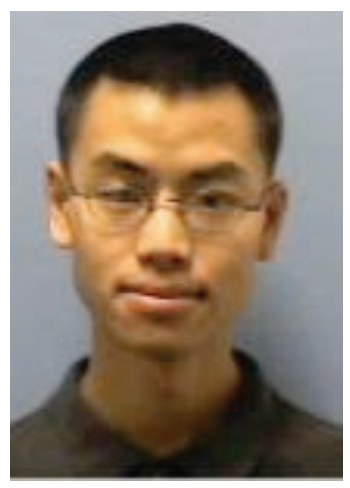

David Yeung earned his B.Sc. in Biochemistry in 2000 and M.Sc. in Chemistry in 2004 from Concordia University, Montreal. He joined Amgen's Analytical Research and Development department later that year and, in 2012, moved to the Chemical Process Research and Development group. 


\begin{tabular}{|ll|ll|}
\hline Date & $30 \mathrm{Apr} 2012$ 16:36:49 \\
\hline Date Stamp & $30 \mathrm{Apr} 2012$ 16:36:49 & \\
\hline File Name & IlsconelNMR-Archiveljcamplyeungl20121117491-5-2_10.dx \\
\hline Frequency (MHz) & 400.13 & Nucleus & $1 \mathrm{H}$ \\
\hline Number of Transients & 16 & Origin & Bruker BioSpin GmbH \\
\hline Original Points Count & 32768 & Owner & shr-ato-nmr1 \\
\hline Points Count & 32768 & SW(cyclical) $(\mathbf{H z})$ & 6410.06 \\
\hline Solvent & DMSO-d6 & Spectrum Offset $(\mathbf{H z})$ & 2400.9126 \\
\hline Sweep Width $(\mathbf{H z})$ & 6409.86 & Temperature (degree C) 21.900 \\
\hline
\end{tabular}
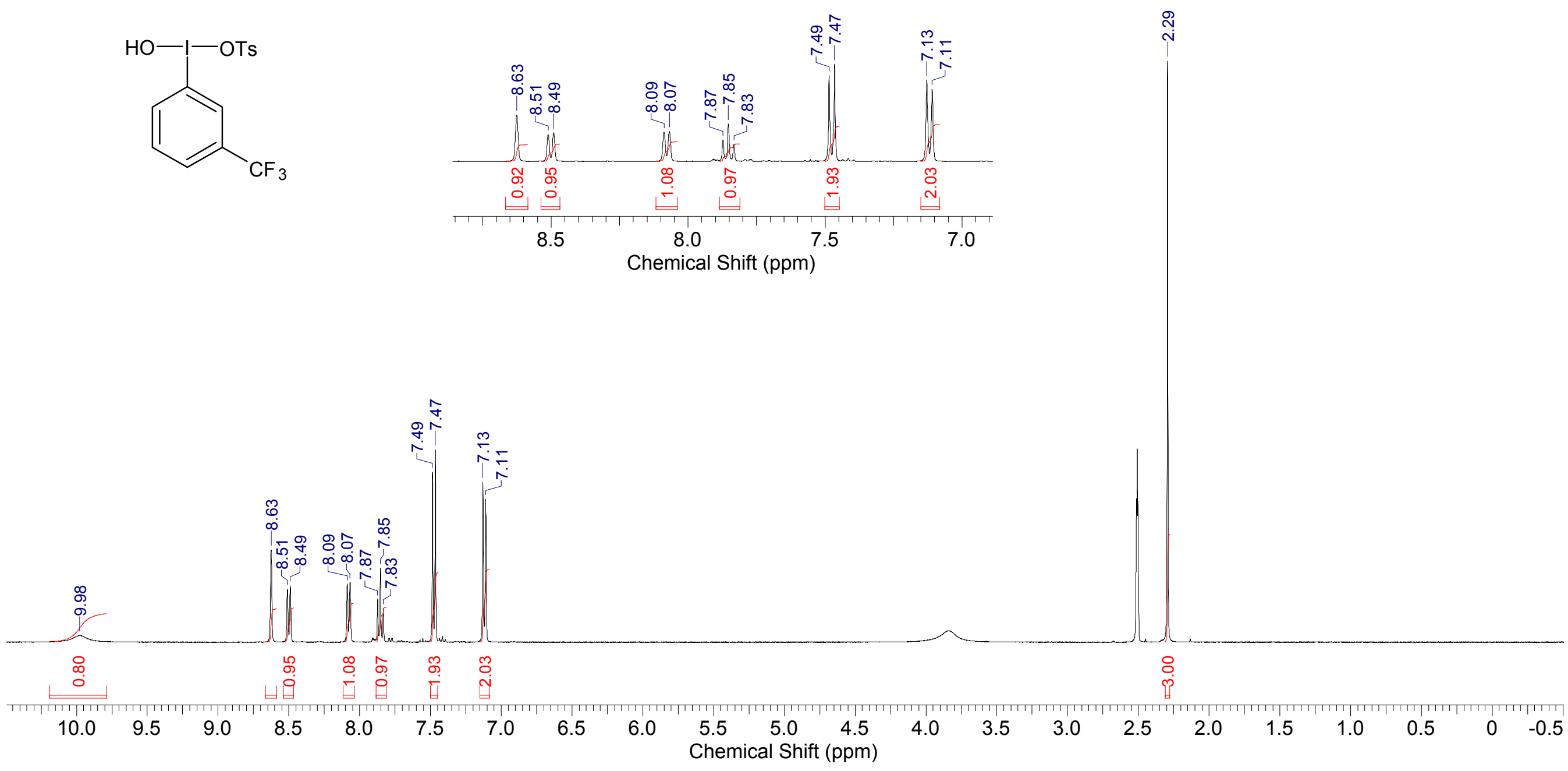


\begin{tabular}{|c|c|c|c|}
\hline Acquisition Time (sec) & 1.4156 & Comment & yeung \\
\hline Date & \multicolumn{3}{|c|}{31 May 2012 14:53:37 } \\
\hline Date Stamp & \multicolumn{3}{|c|}{31 May 2012 14:53:37 } \\
\hline File Name & \multicolumn{3}{|c|}{ IIsconelNMR-Archiveljcamplyeung|2012\117491-5-11_11.dx } \\
\hline Frequency $(\mathrm{MHz})$ & 100.68 & Nucleus & $13 \mathrm{C}$ \\
\hline Number of Transients & 512 & Origin & Bruker BioSpin GmbH \\
\hline Original Points Count & 32768 & Owner & shr-ato-nmr1 \\
\hline Points Count & 32768 & SW(cyclical) (Hz) & 23147.44 \\
\hline Solvent & DMSO-d6 & Spectrum Offset $(\mathrm{Hz})$ & 10018.9746 \\
\hline Sweep Width $(\mathrm{Hz})$ & 23146.73 & Temperature (degree & 27.000 \\
\hline
\end{tabular}

올

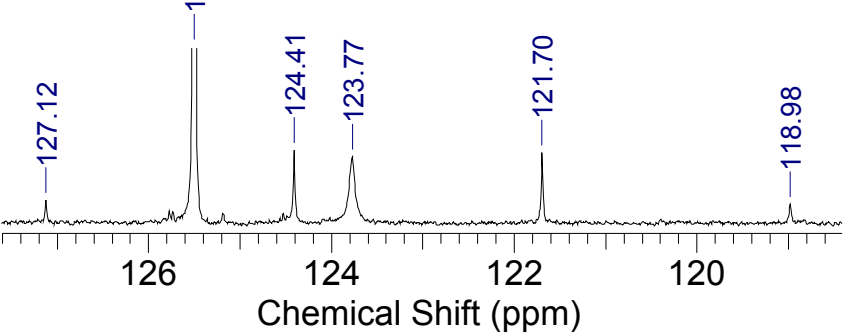

กั

ㅈำ

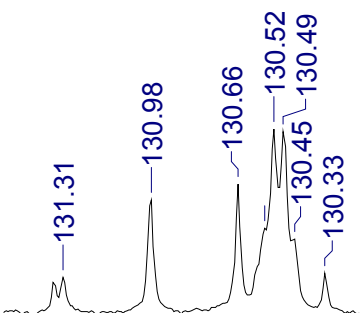

$\begin{array}{llll}131.0 & 130.5 \quad 130.0 & 129.5\end{array}$

Chemical Shift (ppm)

Temperature (degree C) 27.000
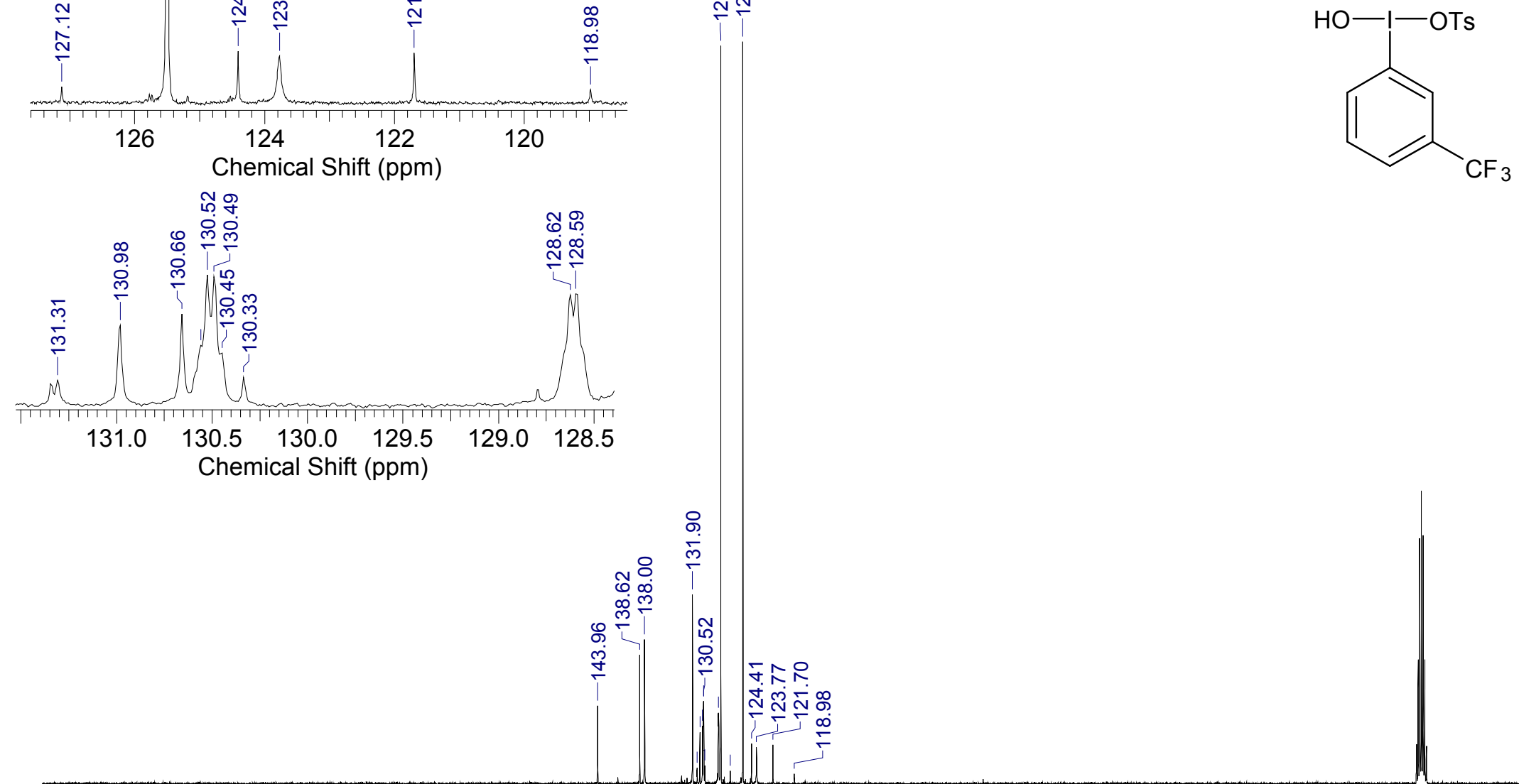


\begin{tabular}{|c|c|c|c|}
\hline Acquisition Time (sec) & 0.8389 & Comment & yeung \\
\hline Date & \multicolumn{3}{|c|}{01 Jun 2012 09:21:12 } \\
\hline Date Stamp & \multicolumn{3}{|c|}{01 Jun 2012 09:21:12 } \\
\hline File Name & \multicolumn{3}{|c|}{ IIsconelNMR-Archiveljcamplyeungl2012/117491-5-12_11.dx } \\
\hline Frequency $(\mathrm{MHz})$ & 376.67 & Nucleus & $19 \mathrm{~F}$ \\
\hline Number of Transients & 16 & Origin & Bruker BioSpin GmbH \\
\hline Original Points Count & 65536 & Owner & shr-ato-nmr1 \\
\hline Points Count & 65536 & $S W(c y c l i c a l)(H z)$ & 78123.80 \\
\hline Solvent & DMSO-d6 & Spectrum Offset $(\mathrm{Hz})$ & -37667.9414 \\
\hline Sweep Width $(\mathrm{Hz})$ & 78122.61 & Temperature (degree & 27.000 \\
\hline
\end{tabular}<smiles>O[AsH3-](O)c1cccc(C(F)(F)F)c1</smiles>

\section{PhF reference}

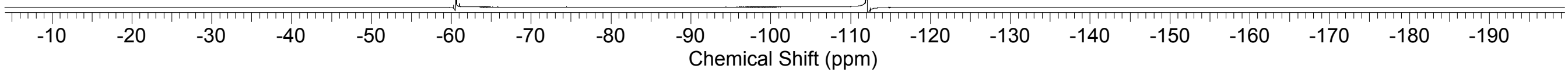




\begin{tabular}{|ll|ll|}
\hline Date & $30 \mathrm{Apr} 2012$ 16:36:49 \\
\hline Date Stamp & $30 \mathrm{Apr} 2012$ 16:36:49 & \\
\hline File Name & IlsconelNMR-Archiveljcamplyeungl20121117491-5-2_10.dx \\
\hline Frequency (MHz) & 400.13 & Nucleus & $1 \mathrm{H}$ \\
\hline Number of Transients & 16 & Origin & Bruker BioSpin GmbH \\
\hline Original Points Count & 32768 & Owner & shr-ato-nmr1 \\
\hline Points Count & 32768 & SW(cyclical) $(\mathbf{H z})$ & 6410.06 \\
\hline Solvent & DMSO-d6 & Spectrum Offset $(\mathbf{H z})$ & 2400.9126 \\
\hline Sweep Width $(\mathbf{H z})$ & 6409.86 & Temperature (degree C) 21.900 \\
\hline
\end{tabular}
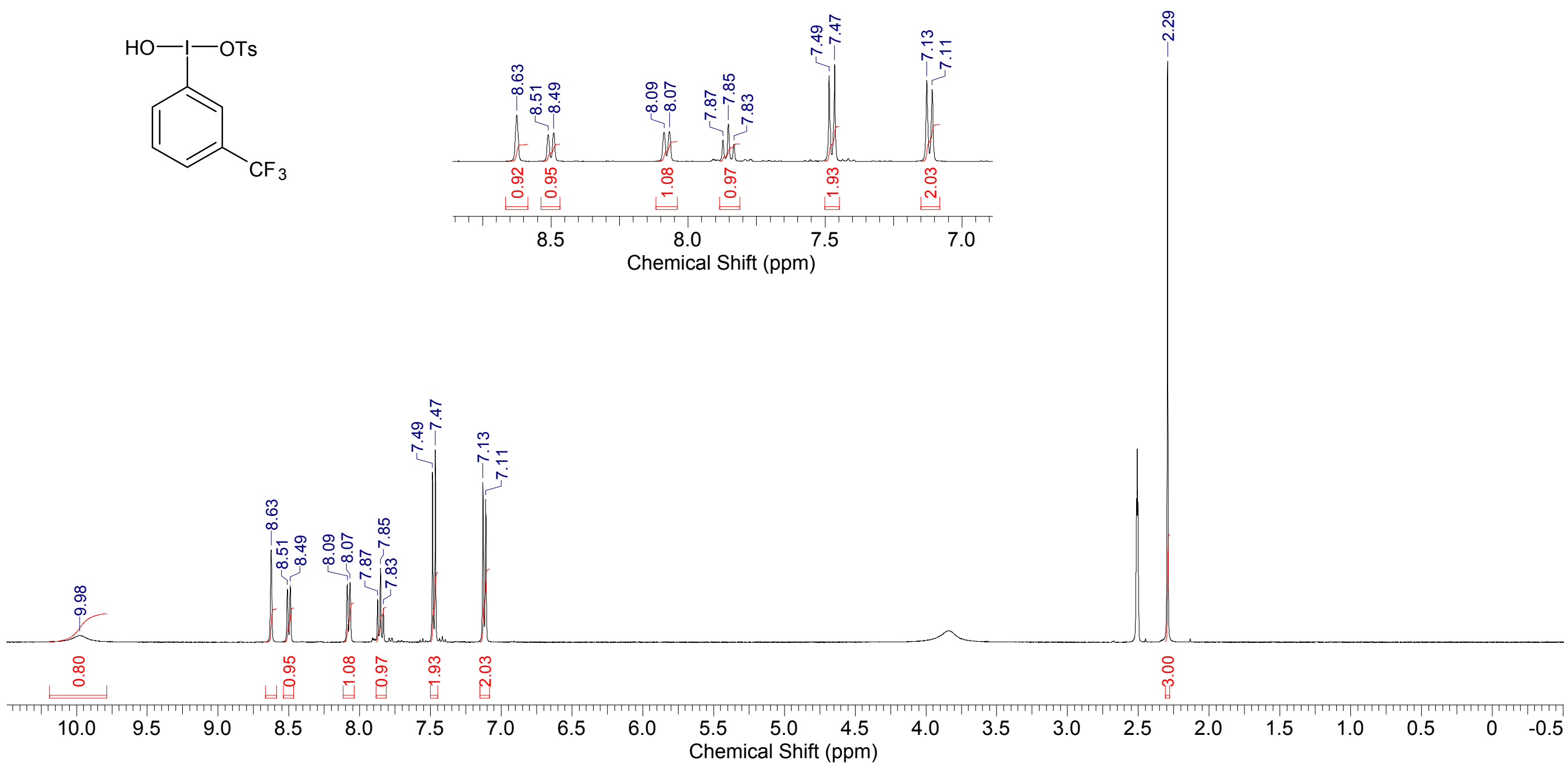


\begin{tabular}{|c|c|c|c|}
\hline Acquisition Time (sec) & 1.4156 & Comment & yeung \\
\hline Date & \multicolumn{3}{|c|}{31 May 2012 14:53:37 } \\
\hline Date Stamp & \multicolumn{3}{|c|}{31 May 2012 14:53:37 } \\
\hline File Name & \multicolumn{3}{|c|}{ IIsconelNMR-Archiveljcamplyeung|2012\117491-5-11_11.dx } \\
\hline Frequency $(\mathrm{MHz})$ & 100.68 & Nucleus & $13 \mathrm{C}$ \\
\hline Number of Transients & 512 & Origin & Bruker BioSpin GmbH \\
\hline Original Points Count & 32768 & Owner & shr-ato-nmr1 \\
\hline Points Count & 32768 & SW(cyclical) (Hz) & 23147.44 \\
\hline Solvent & DMSO-d6 & Spectrum Offset $(\mathrm{Hz})$ & 10018.9746 \\
\hline Sweep Width $(\mathrm{Hz})$ & 23146.73 & Temperature (degree & 27.000 \\
\hline
\end{tabular}

올

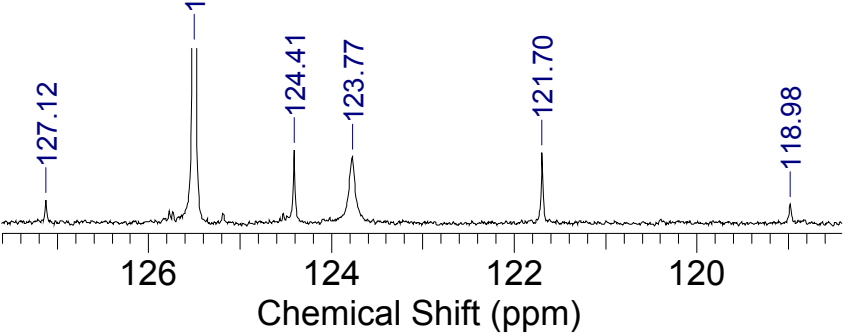

กั

ㅈำ

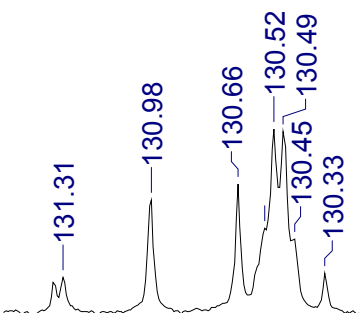

$\begin{array}{llll}131.0 & 130.5 \quad 130.0 & 129.5\end{array}$

Chemical Shift (ppm)

Temperature (degree C) 27.000
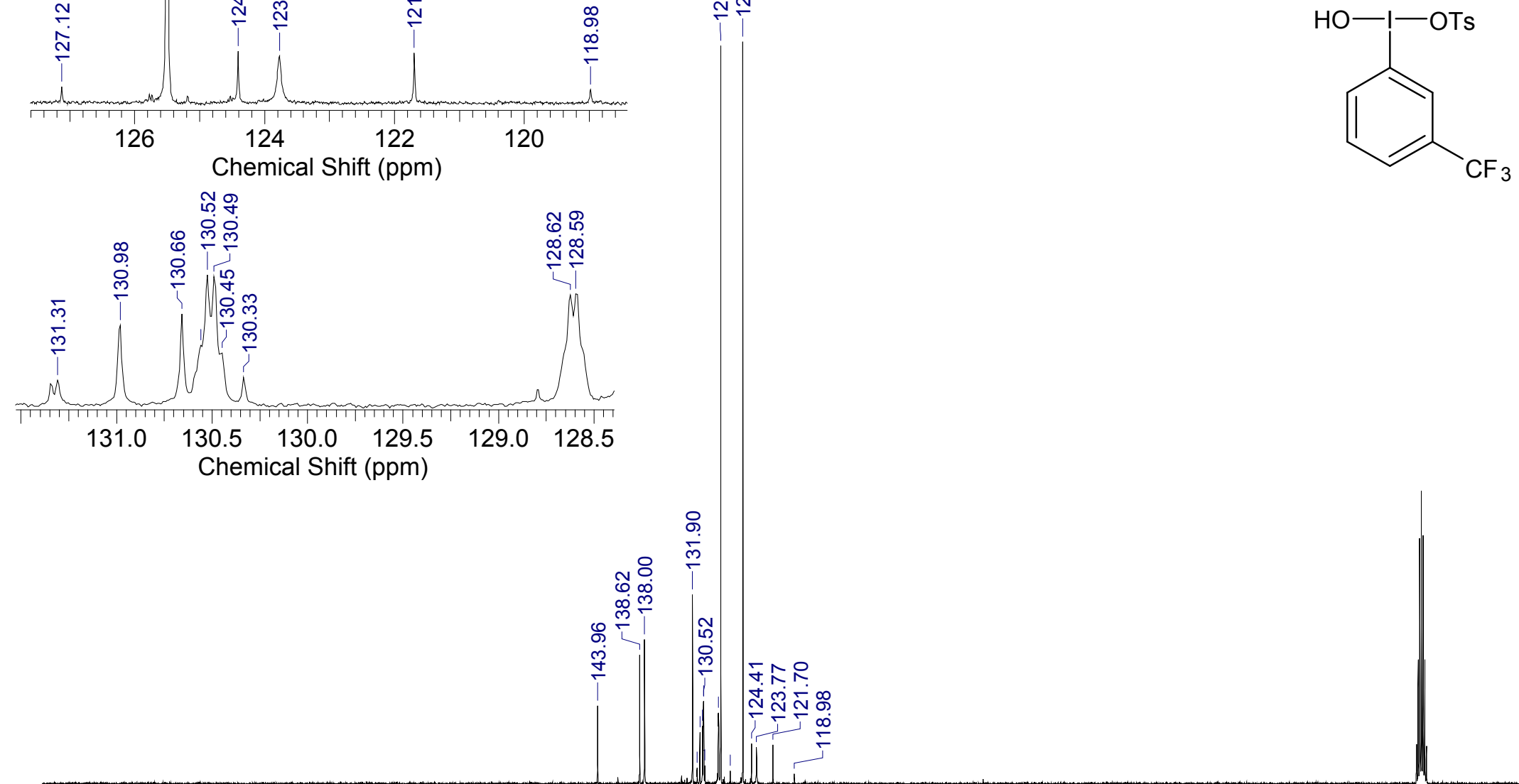


\begin{tabular}{|c|c|c|c|}
\hline Acquisition Time (sec) & 0.8389 & Comment & yeung \\
\hline Date & \multicolumn{3}{|c|}{01 Jun 2012 09:21:12 } \\
\hline Date Stamp & \multicolumn{3}{|c|}{01 Jun 2012 09:21:12 } \\
\hline File Name & \multicolumn{3}{|c|}{ IIsconelNMR-Archiveljcamplyeungl2012/117491-5-12_11.dx } \\
\hline Frequency $(\mathrm{MHz})$ & 376.67 & Nucleus & $19 \mathrm{~F}$ \\
\hline Number of Transients & 16 & Origin & Bruker BioSpin GmbH \\
\hline Original Points Count & 65536 & Owner & shr-ato-nmr1 \\
\hline Points Count & 65536 & $S W(c y c l i c a l)(H z)$ & 78123.80 \\
\hline Solvent & DMSO-d6 & Spectrum Offset $(\mathrm{Hz})$ & -37667.9414 \\
\hline Sweep Width $(\mathrm{Hz})$ & 78122.61 & Temperature (degree & 27.000 \\
\hline
\end{tabular}<smiles>O[AsH3-](O)c1cccc(C(F)(F)F)c1</smiles>

\section{PhF reference}

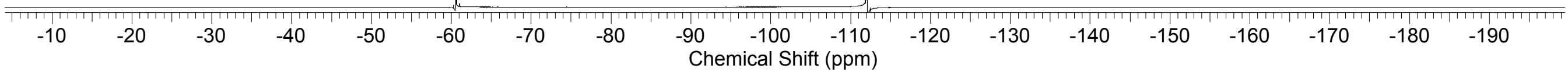

